\title{
A PROPOSTA DE ATUALIZAÇÃo da POLÍTICA NACIONAL DE EDUCAÇ̃̃o ESPECIAL EM RELAÇÃO À INCLUSÃO DE ALUNOS COM DEFICIÊNCIA NO ENSINO SUPERIOR
}

\section{The proposal to update the National Policy of Special Education to the inclusive perspective on inclusion in Higher Education}

\author{
Amabriane da Silva Oliveira Shimite - Universidade Estadual Paulista - UNESP/Brasil \\ Nilson Rogério da Silva - Universidade Estadual Paulista - UNESP/Brasil
}

RESUMO: Objetivou-se problematizar as discussões a respeito da atualização da Política Nacional de Educação Especial na perspectiva inclusiva, em relação à inclusão no ensino superior. Trata-se de um estudo documental da Política de Educação Especial na perspectiva inclusiva, da proposta de atualização da Política de Educação Especial iniciada no ano de 2018 e do documento elaborado, em Maio de 2018, pelo "Laboratório de Estudos e Pesquisas em Ensino e Diferença (LEPED)". O difícil ingresso ao ensino superior, desde a colonização, império e proclamação da república revela a base em que foram desenvolvidas as universidades no Brasil. Por meio de legislações, de programas governamentais e de ações de algumas universidades foram criadas possibilidade para a promoção de ambientes inclusivos no ensino superior. Nesse cenário, estão as propostas de "atualização" da Política Nacional de Educação Especial, com a retirada da perspectiva inclusiva. A ineficiência das ações de inclusão em âmbitos da sociedade é o principal argumento para a atualização da política, sendo necessárias discussões com os diferentes meios sociais, entre eles os de ensino, para a reflexão sobre a compreensão da diferença e, principalmente, a respeito dos direitos humanos. Sendo assim, torna-se imprescindível a reflexão proposta no presente trabalho, no sentido de avaliar se tais "avanços" e "atualizações" são benéficas às pessoas com deficiência no acesso ao ensino superior.

Palavras-chave: Deficiência. Ensino Superior. Inclusão. Política Nacional de Educação Especial.

ABSTRACT: The objective was to problematize the discussions about the updating of the National Policy of Special Education in an inclusive perspective, regarding the inclusion in the higher education. This is a documentary study of the Special Education Policy from an inclusive perspective, the proposal to update the Special Education Policy started in 2018 and the document prepared in May 2018 by the "Laboratório de Estudos e Pesquisas em Ensino e Diferença (LEPED)". The fact of the difficult entry into higher education, since the colonization, empire and proclamation of the republic, highlights the basis on which universities were developed in Brazil. Through the legislation, government programs and actions of some universities paths have been created to promote inclusive environments in higher education. In this scenario are the proposals for "updating" the National Policy of Special Education, with the withdrawal of the inclusive perspective. The inefficiency of social inclusion actions is the main argument for the updating of the policy, and discussions with different social environments, including teaching, are necessary to reflect on what it comprises by 
A proposta de atualização da política nacional de educação especial em relação à inclusão de alunos com deficiência no ensino superior

diversity, and especially on of human rights. Thus, the reflection proposed in this paper is essential to evaluate whether such "advances" and "updates" are beneficial to people with disabilities in the heigher education.

Keywords: Disability. Heigher Education. Inclusion. National Policy of Special Education.

\section{INTRODUÇÃO}

A Política Nacional de Educação Especial na perspectiva inclusiva está sendo reavaliada pelo Ministério da Educação (MEC), com a justificativa de atualizar e revisar as suas propostas, público alvo, sistema de atendimento especializado e nomenclaturas. Contudo, muitos questionamentos surgiram durante esse processo, devido à estrutura e ao planejamento em que se têm realizado as modificações da política, visto que no ano de 2019, essa completou 11 anos de criação e implantação (BRASIL, 2018b; MINUTA, 2018).

Entre as propostas de atualização está a questão da efetividade das ações para inclusão nos sistemas de ensino, embasada por pesquisas científicas que demonstram o processo e o desenvolvimento de estratégias para o atendimento de pessoas com deficiência em todos os níveis de ensino. Entretanto, a maior afirmação para essa ação, de acordo com o MEC, se faz devido: “[...] a necessidade de envolver a inclusão efetiva e não apenas a matrícula dos alunos com deficiência, acessibilidade plena a todos os recursos para aprendizagem e eliminação de barreiras físicas" (BRASIL, 2018b).

Nesse contexto, o "Laboratório de Estudos e Pesquisas em Ensino e DiferençaLEPED” (2018) fez indagações em âmbito científico e político quanto à sistemática em que se realizou o início dessas alterações. Esses pesquisadores questionaram o quanto essa ação tem validade e de fato contribuirá para a melhora do atendimento às necessidades das pessoas com deficiência na Educação e, com maior ênfase nesse trabalho, no seu ingresso, permanência e conclusão no ensino superior.

Em conferência realizada por Mendes (2018) na XIV Jornada de Educação Especial e II Congresso Internacional de Educação Especial e Inclusiva, evento de relevância científica para tal área, que propôs por temática norteadora das discussões de suas conferências, os dez anos da Política Nacional de Educação Especial na Perspectiva Inclusiva. O evento, ocorrido em Maio de 2018 na cidade de Marília/SP, apresentou várias mesas debatedoras sobre a temática, contudo destacou-se a 
conferência proferida por Mendes (2018) cujo título foi: "Possibilidades de avanço para as Políticas de Educação Especial”.

Mendes (2018) apresentou o contexto histórico em que se constituiu a Educação Especial no Brasil, demarcando as legislações consideradas promotoras de 'avanços' nas pesquisas científicas. Também, destacou a ineficiência das ações de inclusão em todos os âmbitos da sociedade, refletindo sobre o que essa compreende por diferença humana e, principalmente, por respeito aos direitos humanos. Por meio da apresentação do percurso histórico da Educação Especial e das legislações sobre a inclusão de pessoas com deficiência, Mendes (2018) discutiu sobre o conceito de simulacro e sobre a superficialidade das ações que versam sobre a inclusão.

Ao analisar a literatura científica sobre a inclusão de pessoas com deficiência no ensino superior são apresentadas as barreiras arquitetônicas, comunicacional, informacional e atitudinal como aspectos interferentes para a construção de uma sociedade acadêmica inclusiva (PLETSCH; LEITE, 2017; SHIMITE, 2017; FERREIRA, 2014). Também, a insuficiência da identificação das necessidades acadêmicas do aluno com deficiência e o enfrentamento das dificuldades pedagógicas pelos docentes do ensino superior (PLETSCH E LEITE, 2017; SHIMITE, 2017). Quanto ao atendimento a política-pública, enfatiza-se a ausência de políticas estruturais no regimento institucional, bem como a organização do atendimento educacional especializado, de um plano de adequação das universidades e o monitoramento das práticas de orientação acadêmica e profissional, quando essas são existentes (CABRAL, 2010; FERREIRA, 2014).

Nesse contexto, questionamentos surgiram sobre o histórico da Educação Especial, sobre o histórico do ensino superior brasileiro, sobre as conquistas legislativas e políticas em relação à inclusão de pessoas com deficiência, a compreensão das diferenças humanas pela sociedade, enfim, porque atualizar a política? Será que esses aspectos são refletidos pela sociedade considerando-os benéficos às pessoas com deficiência? Sua efetividade ocorre no sentido da promoção do desenvolvimento humano de seu público-alvo? De grupos científicos? De grupos políticos e filantrópicos? Ou tratata-se de ações pautadas pela retirada do compromisso com a perspectiva inclusiva?

Educação, Psicologia e Interfaces, Volume 3, Dossiê Inclusão e Diversidade, p. 8-22, 2019. 
A proposta de atualização da política nacional de educação especial em relação à inclusão de alunos com deficiência no ensino superior

Por meio do histórico da Educação Especial e da perspectiva inclusiva no Brasil, bem como da história do ensino superior, se faz necessário discutir a relação entre a Política Nacional de Educação Especial na Perspectiva Inclusiva de 2008 com a proposta de atualização divulgada pelo MEC, sob o ponto de vista das ações de inclusão que ocorrem no ensino superior. Nesse sentido, o objetivo do presente trabalho foi problematizar as discussões a respeito da atualização da Política Nacional de Educação Especial na perspectiva inclusiva em relação à inclusão no ensino superior.

\section{MATERIAL E MÉTODO}

Trata-se de um estudo com base na análise documental proposta em Ludke e André (1986, p. 38), pois de acordo com as autoras esta técnica pode, “[...] [ser procedida] em quaisquer materiais escritos que possam ser utilizados como fonte de informação [...]. Estes incluem desde leis, regulamentos, normas, pareceres [...]”. Para que a análise documental seja realizada, necessita-se “[...] identificar informações factuais nos documentos a partir de questões ou hipóteses de interesse." (LÜDKE; ANDRÉ, 1986, p.38).

Nesse sentido, foi fonte para a discussão proposta nesse trabalho, o atual documento da Política de Educação Especial na perspectiva inclusiva disponibilizado no portal do MEC (BRASIL, 2008). Também, foi utilizada a proposta de atualização da Política de Educação Especial apresentada por dois consultores do MEC, na XIV Jornada de Educação Especial e II Congresso Internacional de Educação Especial e Inclusiva, ocorrida em Maio de 2018 na cidade de Marília/SP e disponível no portal do MEC, no mesmo mês referenciado e no formato de minuta, sendo denominada: Política Nacional de Educação Especial: equitativa, inclusiva e ao longo da vida (MINUTA, 2018).

Como material complementar, no fomento à problematização exposta, foi utilizado o manifesto denominado: "Em defesa da política nacional de educação especial na perspectiva da educação inclusiva: análise e manifestação sobre a proposta do Governo Federal de reformar a PNEEPEI (MEC/2008)” (LEPED, 2018), elaborado pelo “Laboratório de Estudos e Pesquisas em Ensino e Diferença - LEPED” da Faculdade de Educação da Universidade Estadual de Campinas (FE/Unicamp). Esse documento foi divulgado pelo laboratório em sua página na internet e pelas entidades 
científicas da área da Educação Especial em Maio de 2018, durante o processo de consulta pública da atualização da Política de Educação Especial.

Para o procedimento de análise documental foram elecandos temas que auxiliaram na interpretação do contexto dos documentos analisados. Três temas foram estabelecidos, sendo: História da Educação Especial, Legislações sobre a Educação Especial e História do Ensino Superior brasileiro. No tema História da Educação Especial foram obtidas dois tópicos de análise: Diferença e Desenvolvimento humano. Em relação à Educação Especial foi obtido um tópico: judicialização da Educação Especial. Sobre a História do Ensino Superior brasileiro foram obtidos dois tópicos: Influência do Estado e Formação acadêmica para elites sociais.

\section{RESULTADOS E DISCUSSÃO}

A discussão entre a política de educação especial na perspectiva inclusiva e do cenário das políticas públicas para o ensino superior, com ênfase na inclusão de pessoas com deficiência, expôs os progressos realizados no atendimento à pessoa com deficiência na educação básica, fato que promoveu a possibilidade de ingresso no nível superior de ensino dessa minoria social (FERREIRA, 2014). Para a elaboração da política nacional de educação especial na perspectiva inclusiva (BRASIL, 2008) foi constituído um grupo de trabalho composto por quatro membros da Secretaria de Educação Especial e por nove colaboradores nomeados por meio de portaria ministerial, sendo esses professores pesquisadores da área da Educação Especial provindos de instituições de ensino superior de várias regiões do país.

O objetivo da criação desse documento foi esclarecer e promover o conhecimento das legislações em âmbito nacional e internacional dos direitos das pessoas com deficiência, bem como dar conhecimento às diretrizes para o atendimento educacional especializado, ao processo inclusivo e designar seu público-alvo. Nesse sentido, consta no documento: “[...] acompanhar os avanços do conhecimento e das lutas sociais, visando constituir políticas públicas promotoras de uma educação de qualidade para todos os alunos" (BRASIL, 2008, p.5).

Quando a política foi divulgada ofertou-se um mapeamento em termos quantitativo, por meio do uso da estatística descritiva, para apresentar dados de matrículas em instituições públicas e privadas de pessoas com deficiência, na tentativa

Educação, Psicologia e Interfaces, Volume 3, Dossiê Inclusão e Diversidade, p. 8-22, 2019. 
A proposta de atualização da política nacional de educação especial em relação à inclusão de alunos com deficiência no ensino superior

de criar um perfil de ingresso no ensino básico e, após, correlacioná-los com a Educação Especial e com dados sobre acessibilidade em todos os níveis de ensino (BRASIL, 2008). A apresentação, assim como, a discussão desses números colaboraram com a estruturação de um panorama e constituição do cenário de atuação às pessoas com deficiência. Contudo, foram apontados dois aspectos relevantes: a formação dos professores para a atuação na Educação Especial e a acessibilidade arquitetônica.

Nesse sentido, qualificações são elencadas tanto para a descrição da função, na atuação de adaptações e no conjunto de atividades de responsabilidade do atendimento educacional especializado. Entretanto, não se faz menção de qual maneira essas designações serão cumpridas, quais setores públicos serão responsáveis por investir na formação dos professores, quais os programas serão desenvolvidos para atender ao desenvolvimento técnico, instrumental e intelectual desse grupo profissional.

Quanto a aspectos que versam sobre a acessibilidade arquitetônica, desde a vigência da política, ações para normatizar e autorizar novas construções civis públicas e privadas foram empregadas. No entanto, na atualidade, ainda são muitas as barreiras arquitetônicas em cidades, instituições públicas com edificações antigas, entre outros tantos exemplos (PLETSCH; LEITE, 2017). A abordagem de discussões a respeito do desenho universal para a sociedade, nos seus diversos serviços tornou-se ampliada, mas a ausência da efetividade e concretude dessas ações é, ainda, vivenciada diariamente por pessoas com deficiências e com mobilidade reduzida, levando ao questionamento com respeito ao conceito de equidade (OLIVEIRA; NUERNBERG; NUNES, 2013; FERREIRA, 2014; MENDES, 2010; CABRAL, 2010).

Ao retomar o percurso histórico do ensino superior brasileiro e da Educação Especial pode-se refletir como a compreensão das diferenças humanas possui resistência por parte da sociedade, visto a presença da divisão do capital e do trabalho um entrave para a sua efetivação (FERREIRA, 2006). A dificuldade de compreender o lugar social de outro ser humano prejudica o rompimento de barreiras sociais e atitudinais. Skliar (2009, p. 24) ao problematizar a questão da inclusão e da diferença expôs:

É necessário suspeitar desta modalidade de tradução pedagógica que se obstina desde sempre em apontar com o dedo quem e como são os "diferentes", banalizando ao mesmo tempo as diferenças. De fato, o problema não está em saber quais são as diferenças, ou qual é a melhor definição de "diferenças", mas como inventamos ou reinventamos, cotidianamente, aos outros "diferentes", uma alteridade "diferente" (SKLIAR, 2009, p. 24). 
Por meio das legislações apresentadas no histórico da Educação Especial na perspectiva inclusiva foi garantido o direito de acesso ao ensino superior por pessoas com deficiência, nas mesmas condições e solicitações de todos aqueles que são denominados partícipes de um processo seletivo, garantido pela Constituição Federal (BRASIL, 1988) e pela LDBEN no 9.394 de 1996 (BRASIL, 1996). Contudo, o ingresso do aluno com deficiência no ensino superior foi alvo de muitas críticas devido à ausência de atendimento às necessidades da deficiência apresentada.

Com a elaboração da Declaração sobre os direitos da pessoa com deficiência (BRASIL, 2006), da Política Nacional de Educação Especial na perspectiva inclusiva (BRASIL, 2008) e, atualmente, da Lei Brasileira de Inclusão de 2015(BRASIL, 2015), os processos seletivos passaram a atender solicitações de adaptações, tanto de conteúdo e condições de acesso, quanto na disponibilização de profissionais para o atendimento educacional especializado, também, no ensino superior.

O Censo da Educação Superior (INEP, 2018) apresentou o total de 38.272 matrículas de alunos com deficiência. Nesse cenário, o número de alunos com deficiência matriculados no ensino superior enfatizou a demanda desse alunado. Não obstante ao estabelecer uma comparação desse valor com o total de alunos matriculados no ensino superior (8.286.663 matrículas), apenas $0,46 \%$ do total de matrículas correspondem a alunos com deficiência, sendo o número de matrículas em instituições públicas de 14.293 matrículas e de 23.979 matrículas em privadas. A crescente demanda ocorre pelas ações de promoção para ingresso, mediante o cumprimento de exigências legislativas (FERREIRA, 2014). De acordo com Pletsch e Leite (2017, p.103), “[...] apesar do avanço na produção de conhecimento sobre a inclusão no ensino superior, esse ainda está muito aquém da demanda estudantil que cresce de forma acelerada".

Ao associar o contexto histórico do ensino superior ao da Educação Especial percebe-se que, o percurso histórico do ensino superior brasileiro teve início na época em que o país era colônia de Portugal (FÁVERO, 2006). Nesse período, muitos países já contavam com um sistema universitário de ensino, enquanto no Brasil a coroa portuguesa mantinha esforços para retardar a implantação de universidades, em princípio por desinteresse e por julgar tal ação desnecessária. Contudo, ainda no século

Educação, Psicologia e Interfaces, Volume 3, Dossiê Inclusão e Diversidade, p. 8-22, 2019. 
A proposta de atualização da política nacional de educação especial em relação à inclusão de alunos com deficiência no ensino superior

XIX, a dificuldade em acessar as universidades do continente Europeu, acabou por implantar o ensino superior na colônia (SCHWARTZMAN, 2013).

O ensino superior brasileiro foi concebido no modelo de instituto isolado de natureza profissionalizante, possuindo cursos de engenharia militar e medicina aplicada em uma organização instituída por faculdades isoladas, que causaram desde o início de suas funções, questionamentos quanto sua estrutura e funcionamento (SOARES et al., 2002). Com a falta de interesse em instituir no Brasil o ensino superior, Fávero (2006) apresenta que a instituição desse nível de ensino, desde a sua concepção, sofreu interferências e carências organizacionais, as quais afetam até a contemporaneidade o exercício de suas funções no âmbito da educação. Outra questão foi quanto ao Império e a Proclamação da República, que provocaram importantes mudanças no contexto social do Brasil e na sua Educação. Essas modificações ajudaram a melhor organizar o ensino superior, no sentido de apropriar o saber científico à identidade das universidades no Brasil. Contudo, ainda pautado na dualidade estrutural e no acesso a educação à elite intelectualizada (SOARES et al., 2002).

Saviani (2008) analisando o histórico do ensino superior brasileiro destacou a descentralização desse nível de ensino, provida pela Constituição da República que retirou a característica privativa do Estado, com a justificativa de diversificar a possibilidade de acesso ao ensino superior. Assim, as novas universidades foram iniciativas de grupos políticos, intelectuais e educadores interessados no ensino superior, demonstrando a pouca experiência administrativa, o cunho político e ideológico que deram características ao funcionamento desse nível de ensino no país e a sua política de Estado.

As políticas-públicas em Educação Especial no Brasil emergiram a partir do final de década de 1960 (FERREIRA, 2006). Até esse período o país apresentava algumas ações quanto ao atendimento às pessoas com deficiência em âmbito escolar, porém tais atos eram restritos as instituições de ensino especializadas públicas e, principalmente, privadas. Nos anos de 1970 e subsequentes, a história da Educação no Brasil apresentou reformas educacionais que abarcaram a Educação Especial, questionando os discursos de normalização e integração sustentados, até o presente momento, pelas instituições que atendiam as pessoas com deficiência (CABRAL, 2010; MENDES, 2010).

Educação, Psicologia e Interfaces, Volume 3, Dossiê Inclusão e Diversidade, p.8-22, 2019. 
Nesse contexto, a Educação Especial passou a ser prioritária nos planos setoriais de educação, sendo considerada na edição de normas e planos políticos de âmbito nacional, como na Lei $\mathrm{n}^{\mathrm{o}}$ 5.692/71 de reforma de primeiro e segundo graus (BRASIL, 1971). Assim foram criados nos sistemas de ensino, setores de educação especial, bem como carreiras especializadas em educação especial na educação escolar e a constituição das equipes de reabilitação, surgindo o ensino itinerante e as salas de recursos (MAZZOTA, 2010; CABRAL, 2010; FERREIRA, 2006).

Contudo, Kassar, Rebelo e Oliveira (2019), Ferreira (2006), Mazzota (2005) e Januzzi (1992) relataram que o discurso da integração e a criação de serviços de atendimento ao aluno com deficiência passaram a apresentar uma atuação maciça de instituições especializadas, demonstrando a não prioridade das políticas sociais quanto ao discurso sobre ambientes menos restritivos do direito ao convívio com seus pares, considerados normais. As abordagens legislativas, por meio de normas e documentos dirigidos aos alunos com deficiência, demonstraram o desenvolvimento das políticas públicas, contudo, como afirma Ferreira (2006, p. 88):

[...] a concentração de ações da educação especial em instituições filantrópicas e nas escolas comuns por meio das classes especiais apresentaram dois espaços educacionais que permaneceram hegemônicos até o final dos anos 1990 (FERREIRA, 2006, p. 88).

Historicamente, críticas foram e, são na atualidade, realizados ao paradigma da integração, devido à ausência de capacitação dos alunos considerados especiais para o convívio social, na escola e na sociedade (MENDES, 2010). Essa ação ocorreu pela redução da problemática da deficiência ao âmbito da instituição escolar, ao otimismo quanto ao atendimento pedagógico especializado e a atribuição à escola como primeira responsável pela transformação social sobre a educação do aluno com deficiência (FERREIRA, 2006; SKLIAR, 2009; CABRAL, 2010).

Ações para garantir o acesso a pessoas com deficiência ao ensino superior, como o Programa de Apoio e Plano de Reestruturação das Universidades Federais (REUNI), do Programa de Acessibilidade para o ensino superior (INCLUIR) e da instituição de Núcleos de acessibilidade em universidades federais e estaduais públicas (BRASIL, 2018a) tem ocupado um papel importante. Embora o desdobramento das ações da Educação Especial na perspectiva inclusiva, ainda se concentre no ensino básico, essas

Educação, Psicologia e Interfaces, Volume 3, Dossiê Inclusão e Diversidade, p. 8-22, 2019. 
A proposta de atualização da política nacional de educação especial em relação à inclusão de alunos com deficiência no ensino superior

características demonstram o processo de inclusão sendo desenvolvido durante a escolarização, por intermédio das conquistas da política-pública na área da Educação Especial no Brasil, em um árduo caminho propiciado pelas legislações e pelo cumprimento das mesmas (SHIMITE, 2017).

O contexto histórico do ensino superior auxilia na compreensão do cenário de impedimento do Brasil, enquanto colônia, na implantação de universidades, visto que os portugueses retardaram ao máximo o estabelecimento de instituições de ensino superior (FÁVERO, 2006). Essa intervenção dos portugueses impactou toda a estrutura inicial desse nível de ensino, devido à influência dos moldes europeus as universidades criadas no Brasil, como também dos tipos de formações de nível superior instituídos na colônia.

Esse cenário possibilitou a criação da universidade atrelada, em um período histórico posterior, ao Estado. Além disso, condicionou a oferta de formação ao ensino profissional por meio de institutos isolados de natureza profissionalizante e detentores das condições de acesso (SOARES et al., 2002). O fato do difícil ingresso ao ensino superior, desde a colonização até a proclamação da república, destaca a base em que foram desenvolvidas as universidades no Brasil, sendo direcionada para uma elite social e ainda sim, limitada a formação profissional de interesse do Estado.

A reflexão realizada por meio da promoção da atualização da Política Nacional de Educação Especial na perspectiva inclusiva contesta a realidade dos "avanços", pois, criticando de maneira intencional as dificuldades de atuação do atendimento educacional especializado, se reduz as ações da perspectiva inclusiva a esse aspecto (MENDES, 2018). No entanto, a crítica ao processo inclusivo por parte do MEC não ocorre com foco na melhoria, na institucionalização do processo inclusivo nos níveis de ensino e na busca de incentivo financeiro do Estado, considerando o contexto histórico como o marco principal para a proposição da atualização, mas direcionando à filantropia e as consultorias em educação inclusiva, como solução para a constituição da educação especial equitativa, inclusiva e ao longo da vida (MINUTA, 2018; LEPED, 2018). Nesse sentido, não se reflete, em termos de sociedade, sobre a pessoa com deficiência, mas sobre os benefícios provindos de sua condição para ganhos lícitos em detrimento da conduta social, ética e moral em relação à compreensão das diferenças humanas e fomento ao desenvolvimento humano.

Os aspectos que motivam a atualização da política de educação especial impactam diretamente no acesso ao ensino superior, prejudicando todo o esforço dos 
alunos com deficiência que ingressam esse nível de ensino e apresentam-se como demanda fundamentadora para incentivar o processo seletivo com adaptações, ingresso, modificações arquitetônicas e apoio ao processo de ensino-aprendizado atendendo suas necessidades humanas. O histórico do ensino superior apresenta o quanto esse nível de ensino é seletivo em relação ao ingresso, controlado pelo Estado em termos de desenvolvimento institucional e cerceado de verbas públicas para o investimento no processo inclusivo (PLETSCH; LEITE, 2017; SHIMITE, 2017; FERREIRA, 2014; CABRAL, 2010). Tais aspectos impactam no desenvolvimento humano da pessoa com deficiência, em políticas-públicas para essa minoria e retiram a oportunidade da constituição de sua autonomia e identidade na sociedade.

\section{CONSIDERAÇÕES FINAIS}

O objetivo do presente trabalho foi problematizar as discussões a respeito da atualização da Política Nacional de Educação Especial na perspectiva inclusiva frente à inclusão no ensino superior, por meio do resgate histórico e da compreensão das diferenças sociais.

O fato do difícil ingresso ao ensino superior, desde a colonização, o império e a proclamação da república, destaca a base em que foram desenvolvidas as universidades no Brasil, sendo direcionadas para uma elite social e ainda sim, limitada a formação profissional de interesse do Estado. Nesse sentido, a discussão entre a política de educação especial na perspectiva inclusiva e do cenário das políticas públicas para o ensino superior, com ênfase na inclusão de pessoas com deficiência, expôs os progressos realizados no atendimento à pessoa com deficiência no ensino básico, possibilitando até, seu possível ingresso, no nível superior de ensino.

Por meio de legislações, de programas governamentais e de ações de algumas universidades foram criados trajetos para a promoção de ambientes inclusivos no ensino superior. Contudo, ainda insuficientes em número e em ações efetivas para a promoção da permanência e conclusão de cursos superiores por pessoas com deficiência. Pesquisas científicas apresentam e avaliam o acesso ao ensino superior por pessoas com deficiência, enfatizando ações de núcleos de acessibilidade e ações individuais para o desenvolvimento de adaptações pedagógicas e promoção do atendimento educacional especializado nesse nível de ensino.

Educação, Psicologia e Interfaces, Volume 3, Dossiê Inclusão e Diversidade, p. 8-22, 2019. 
A proposta de atualização da política nacional de educação especial em relação à inclusão de alunos com deficiência no ensino superior

No entanto, a realidade de ausência de incentivo público para o cumprimento das designações previstas nas legislações que tratam da inclusão e, principalmente, na Política Nacional de Educação Especial na perspectiva inclusiva é latente em todos os níveis de ensino. Por um lado, historicamente, o ensino superior foi pautado no desenvolvimento para uma elite social e para uma formação profissional de interesse do Estado, como o incentivo de escolas médicas e de engenharias, por exemplo. Em outro, a dificuldade em progredir de maneira concreta, por meio de ações de fomento a inclusão no âmbito da educação, para a promoção do direito da pessoa com deficiência a constituir-se enquanto ser humano é afetado pela dificuldade social da compreensão das diferenças humanas.

Ainda nesse cenário estão as propostas de "atualização" da Política Nacional de Educação Especial, com a retirada da perspectiva inclusiva. A maior afirmação para essa ação, de acordo com o MEC, se faz devido ao argumento de atender a necessidade da inclusão ser efetiva. Contudo, a ineficiência das ações de inclusão está em todos os âmbitos da sociedade, sendo necessárias ações inclusivas nos diferentes meios sociais, entre eles os de ensino, para a reflexão sobre o que essa compreende por diferença humana e, principalmente, a respeito dos direitos humanos.

O histórico da Educação Especial demonstra uma realidade diversa do que se compreende por inclusão e a superficialidade das suas ações na atualidade. Sendo assim, torna-se imprescindível a reflexão proposta no presente trabalho, no sentido de avaliar se tais "avanços" e "atualizações" são benéficas às pessoas com deficiência, como também se sua efetividade ocorre no sentido da promoção do desenvolvimento de seu público-alvo ou de grupos científicos, políticos e filantrópicos como a história pôde apresentar.

\section{REFERÊNCIAS BIBLIOGRÁFICAS}

BRASIL. Decreto ${ }^{\circ} 3.928$, de 20 de dezembro de 1999. Regulamenta a Lei $n^{\circ} 7.853$, de 24 de outubro de 1974, sobre a Política Nacional de integração da pessoa portadora de deficiência. Diário oficial [da] República Federativa do Brasil, Brasília, DF, 21 dez. 1999. Disponível em: 〈http://www.planalto.gov.br/ccivil_03/decreto/d3298.htm> Acesso em: 10 maio. 2018.

BRASIL. Lei n ${ }^{\circ}$ 9.394, de 20 de dezembro de 1996. Lei de Diretrizes e Bases na Educação Nacional -LDB. Diário oficial [da] República Federativa do Brasil, Brasília, DF, 23 dez. 1996. 
BRASIL. Lei no 13.146, de 6 de julho de 2015. Lei Brasileira de Inclusão da Pessoa com Deficiência. Diário oficial [da] República Federativa do Brasil, Brasília, DF, 7 jun. 2015. Disponível em: <http://www.planalto.gov.br/ccivil_03/_Ato20152018/2015/Lei/L13146.htm> Acesso em: 10 jan. 2018.

BRASIL. Ministério da Educação. Secretaria de Ensino Superior. Programas de acesso ao ensino superior.2018a.Disponível em:

<http://portal.mec.gov.br/sesu/arquivos/pdf/livrosesu.pdf〉. Acesso: 10 maio 2018.

BRASIL.Ministério da Educação. Atualização da Política de Educação Especial na Perspectiva Inclusiva. 2018b. Disponível em: <http://portal.mec.gov.br/ultimasnoticias/202-264937351/62961-politica-de-educacao-especial-devera-passar-poratualizacao>. Acesso em: 06 maio 2018.

BRASIL. Ministério da Educação. Política de Educação Especial na Perspectiva Inclusiva. 2008. Disponível em:

<http://portal.mec.gov.br/arquivos/pdf/politicaeducespecial.pdf>. Acesso: $18 \mathrm{de}$ abr. 2018.

BRASIL. Lei ${ }^{\circ}$ 5.692, de 11 de agosto de 1971. Lei de Diretrizes e Bases para o ensino de $1^{\circ}$ e $2^{\circ}$ grau. Diário oficial [da] República Federativa do Brasil, Brasília, DF, 11 ago. 1971.

CABRAL, L. S. A. Orientação acadêmica e profissional dos estudantes com deficiência: perspectivas internacionais. 2010. 218f. Tese (Doutorado em Educação Especial) - Universidade Federal de São Carlos, UFSCAR, São Carlos, 2010.

FÁVERO, M. L. A. A universidade no Brasil: das origens à Reforma Universitária de 1968. Educar, Curitiba, n. 28, p. 17-36, 2006.

FÁVERO, M. L. A. Universidade \& Poder: Análise crítica/Fundamentos históricos:1930-45. Rio de Janeiro: Achiamé, 1980. 208 p.

FERREIRA, N. M. C.; Educação inclusiva no ensino superior: análise de políticas educacionais para a pessoa com deficiência na Universidade Federal do Maranhão. Revista Educação e Emancipação, SãoLuis/MA, v. 7, n. 1,p.59-82, jan./jun. 2014.

FERREIRA, J. R. Educação Especial , inclusão e política educacional: notas brasileiras. In: RODRIGUES, D. Inclusão e Educação: Doze olhares sobre educação inclusiva. São Paulo: Summus, 2006. p.85-113.

INEP. Instituto Nacional de Educação e Pesquisa. Censo da Educação Básica 2017: resumo técnico. Brasília: Instituto Nacional de Estudos e Pesquisas Educacionais Anísio Teixeira, 2018.

JANNUZZI, G. M. A. A luta pela Educação do Deficiente Mental no Brasil, 2. ed. Campinas: Autores Associados, 1992. 123 p. 
Jornada de Educação Especial (XIV) e Congresso Internacional de Educação (II). 2018. Disponível em: <http://ocs-jee.marilia.unesp.br/index.php/JEE/XIVJEE> . Acesso em: 20 maio. 2018.

KASSAR, M. C.M.; REBELO, A. S.; OLIVEIRA, R. T. C. Embates e disputas na política nacional de Educação Especial brasileira. Educ. Pesqui., São Paulo, v. 45, e217170, 2019.

LEPED. UNICAMP. Em defesa da política nacional de educação especial na perspectiva da educação inclusiva: análise e manifestação sobre a proposta do Governo Federal de reformar a PNEEPEI (MEC/2008). Campinas: Unicamp, 2018. Disponível em: <https://inclusaoja.files.wordpress.com/2018/05/texto-de-anc3a1lisedos-slides-sobre-a-reforma-da-pneepei-final1.pdf> . Acesso: 20 maio 2018.

LÜDKE, M.; ANDRÉ, M.E.D.A. Pesquisa em educação: abordagens qualitativas. São Paulo, EPU, 1986. 98 p.

\section{MAZZOTTA, M. J. S. Educação Especial no Brasil: História e Políticas}

Públicas, 5.ed. São Paulo: Cortez Editora, 2005. 232 p.

MENDES, E. G. Breve histórico da educação especial no

Brasil.Revista Educación y Pedagogía, Medellín, Universidad de Antioquia, Facultad de Educación, v. 22, n. 57,p. 93-109,maio/ago. 2010.

MENDES, E. G. Conferência: Possibilidades de avanço para as Políticas de Educação Especial. In:Jornada de Educação Especial (XIV) e Congresso Internacional de Educação (II). 2018. Disponível em: <http://ocs-

jee.marilia.unesp.br/index.php/JEE/XIVJEE> . Acesso em: 20 maio.2018.

MINUTA da política de educação especial. Política nacional de educação especial: equitativa, inclusiva e Ao longo da vida. [S. 1.: s. n.], 2018.

OLIVEIRA, C.M.; NUERNBERG, A.H.; NUNES, C. H. S.S. Desenho universal e avaliação psicológica na perspectiva dos direitos humanos. Avaliação Psicológica, v.12, n.3, p. 421-428, 2013.

PLETSCH, M.D.; LEITE, L.P. Análise da produção científica sobre a inclusão no ensino superior. Educar em Revista, Curitiba, Brasil, v. 33, n. especial 3, p. 87-106, dez. 2017.

SAVIANI, D. Desafios da construção de um sistema nacional articulado de educação. Trab. educ. saúde [online]. 2008, vol.6, n.2, pp.213-232. Disponível em: http://dx.doi.org/10.1590/S1981-77462008000200002. Acesso: 10 maio 2018.

SCHWARTZMAN, S. A crise na universidade. Revista Ensino Superior. n.10, p.5670, jul -set. 2013. 
SHIMITE, A. S. O. Inclusão e Educação Tecnológica em foco: percepções de uma aluna com deficiência visual, de seus professores e de seus colegas. 2017. $107 \mathrm{f}$. Dissertação (Mestrado em Educação) -Universidade Estadual Paulista, Faculdade de Filosofia e Ciências, Marília, 2017.

SOARES, M.S.A. et al. Educação Superior no Brasil. Porto Alegre: IESALC, 2002. Disponível em: < http://flacso.redelivre.org.br/files/2013/03/1109.pdf>. Acesso: 12 maio 2018.

SKLIAR, C. A inclusão que é "nossa" e a diferença que é do "outro". In: RODRIGUES, D. Inclusão e Educação: Doze olhares sobre educação inclusiva. São Paulo: Summus, 2006. p.15-63.

\section{Credenciais da/os autora/es}

SHIMITE, Amabriane da Silva Oliveira. Doutoranda e Mestra pelo programa de Pós-Graduação em Educação da Universidade Estadual Paulista - UNESP, câmpus Marília/SP, na linha de pesquisa em Educação Especial. Atua em trabalhos com a temática: deficiência e Ensino Superior. Também é especialista em Gestão do Controle de Qualidade em Alimentos pela Faculdade Tecnologia de Marília - FATEC e em Educação Especial pelo Centro Universitário Claretiano- CEUCLAR. Foi professora e responsável pelo projeto" Inclusão de alunos com deficiência no curso superior de Tecnologia em Alimentos - FATEC Marília". É membro do grupo de pesquisa Trabalho, Saúde e Deficiência pelo CNPq. E-mail: dsshimite@ gmail.com

SILVA, Nilson Rogério da. Mestre em Engenharia de Produção pela Universidade Federal de São Carlos, doutor em Educação Especial pela Universidade Federal de São Carlos. PosDoutorado pela Faculdade de Medicina de Ribeirão Preto da Universidade de São Paulo. Professor Associado junto ao Curso de Terapia Ocupacional da Universidade Estadual Paulista Unesp Campus de Marília, Livre-Docência em Terapia Ocupacional em Saúde do Trabalhador. Docente junto ao Programa de Pós-Graduação em Educação da Unesp Câmpus de Marília/SP, Linha: Educação Especial. Coordena o Grupo de Pesquisa Trabalho, Saúde e Deficiência Unesp Câmpus de Marília, Participa dos Grupos de Pesquisas Aprendizagem, Desenvolvimento e Saúde Mental do Escolar, da Universidade de São Paulo e Estudos em Terapia Ocupacional: Ocupação, Reabilitação Física, Tecnologia Assistiva e Funcionalidade - UFSCar. E-mail: nilson@marilia.unesp.br

Endereço para correspondência: Amabriane da Silva Oliveira Shimite. E-mail: dsshimite@gmail.com

Como citar este artigo (Formato ABNT): SHIMITE, Amabriane da Silva Oliveira; SILVA, Nilson Rogério da. A proposta de atualização da política nacional de educação especial em relação à inclusão de alunos com deficiência no ensino superior. Educação, Psicologia e Interfaces, Volume 3, Dossiê Inclusão e Diversidade, p. 8-22, 2019. ISSN: 2594-5343. DOI: https://doi.org/10.37444/issn-2594-5343.v3i4.191

Recebido: $27 / 08 / 2019$.

Aceito: 20/11/2019.

Educação, Psicologia e Interfaces, Volume 3, Dossiê Inclusão e Diversidade, p. 8-22, 2019. 